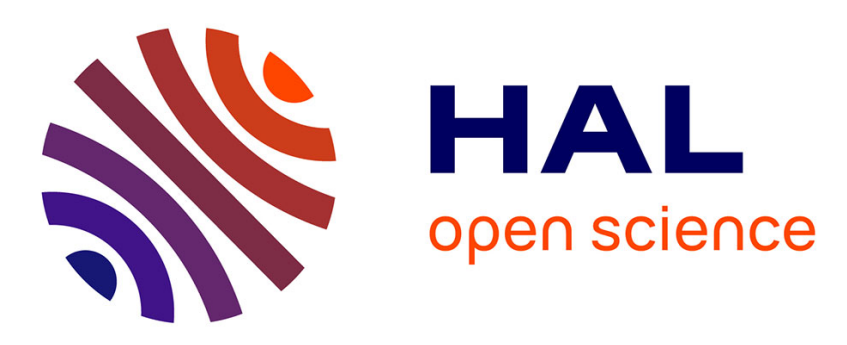

\title{
Synthesis and characterization of N-heterocyclic carbene dithiocarbamate platinum complexes with antitumoral activity
}

Raphaël Verron, Thierry Achard, Cendrine Seguin, Sylvie Fournel, Stéphane Bellemin-Laponnaz

\section{To cite this version:}

Raphaël Verron, Thierry Achard, Cendrine Seguin, Sylvie Fournel, Stéphane Bellemin-Laponnaz. Synthesis and characterization of N-heterocyclic carbene dithiocarbamate platinum complexes with antitumoral activity. European Journal of Inorganic Chemistry, 2020, 2020 (26), pp.2552-2557. 10.1002/ejic.202000329 . hal-02997509

\section{HAL Id: hal-02997509 \\ https://hal.science/hal-02997509}

Submitted on 10 Nov 2020

HAL is a multi-disciplinary open access archive for the deposit and dissemination of scientific research documents, whether they are published or not. The documents may come from teaching and research institutions in France or abroad, or from public or private research centers.
L'archive ouverte pluridisciplinaire HAL, est destinée au dépôt et à la diffusion de documents scientifiques de niveau recherche, publiés ou non, émanant des établissements d'enseignement et de recherche français ou étrangers, des laboratoires publics ou privés. 


\title{
Synthesis and characterization of $\mathrm{N}$-heterocyclic carbene dithiocarbamate platinum complexes with antitumoral activity.
}

\author{
Raphaël Verron, ${ }^{[a]}$ Thierry Achard, ${ }^{*[a]}$ Cendrine Seguin, ${ }^{[b]}$ Sylvie Fournel ${ }^{[b]}$ and Stéphane Bellemin- \\ Laponnaz ${ }^{*[a]}$
}
[a] R. Verron, Dr T. Achard, Dr S. Bellemin-Laponnaz
Institut de Physique et Chimie des Matériaux de Strasbourg (IPCMS)
Université de Strasbourg-CNRS UMR 7504
23 rue du Loess, BP 43, 67034 Strasbourg Cedex 2, France
E-mail: bellemin@unistra.fr
http://www.ipcms.unistra.fr
[b] C. Seguin, Pr Dr. S. Fournel
Faculté de Pharmacie,
Université de Strasbourg-CNRS UMR 7199
74 Route du Rhin, BP 60024, 67401 Illkirch Cedex, France
http://camb.cnrs.fr

Supporting information for this article is given via a link at the end of the document.

\begin{abstract}
A series of platinum(II) complexes bearing N-heterocyclic carbene $\mathrm{NHC}$ of the type $[(\mathrm{NHC}) \mathrm{PtX}(\mathrm{L})]$ where $\mathrm{L}$ is a dithiocarbamate ligand and $\mathrm{X}$ iodide were prepared and fully characterized. The molecular structure of one derivative was determined by single-crystal $\mathrm{X}$-ray analyses confirming that the dithiocarbamate is acting as a bidentate ligand to the metal. All complexes demonstrated potent in vitro antiproliferative activities against cancer cells. Mechanistic investigations revealed that mitochondrial dysfunction and ROS (Reactive Oxygen Species) production were correlated with the cytotoxic process induced by these complexes.
\end{abstract}

\section{Introduction}

Since its approval four decades ago, ${ }^{[1]}$ cisplatin $\mathrm{PtCl}_{2}\left(\mathrm{NH}_{3}\right)_{2}$ has become an important chemotherapeutic drug for various cancer types including ovarian, lung, testicular, bladder cancers but also lymphoma, myeloma and melanoma, mostly in combination with other drugs. ${ }^{[2]}$ Although it has demonstrated its usefulness, several severe side effects still greatly limit the effectiveness of the drug and thus the development of new platinum-based drugs with reduced toxicity remains a dynamic and highly active field of research. In this context, the use of $\mathrm{N}$-heterocyclic carbene ligands $(\mathrm{NHC})^{[3,4]}$ has emerged as an attractive strategy to develop promising substitutes of cisplatin. ${ }^{[5]}$ Platinum NHC complexes but also $\mathrm{Au}, \mathrm{Ag}, \mathrm{Pd}, \mathrm{Cu}, \mathrm{Ru}$ or Ir $\mathrm{NHC}$ complexes have been investigated for the development of potential metallodrugs. ${ }^{[6,7]}$

The N-heterocyclic carbene ligands allow generating highly stable $\mathrm{Pt}$ complexes even in the presence of reactive functions and these compounds may also be easily functionalized by the introduction of additional ligands such as for example nitrogenbased ligands, enabling high molecular structure diversity. ${ }^{[8]}$

A known deactivation pathway of platinum-based drugs is due to the presence of biological reactive functions -such as thiol functions- that react with the metal prior to penetrate the targeted cell. ${ }^{[9]}$ A strategy to avoid such deactivation may be to introduce sulfur-containing molecules as protective agents which could mitigate the toxicity side effects of $\mathrm{Pt}^{[10]}$
Dithiocarbamates have displayed promising biological properties including antiviral and anti-cancer activities. ${ }^{[11]}$ Notably, some monofunctional platinum(II) dithiocarbamate complexes have demonstrated better in vitro anticancer activities compared to cisplatin. ${ }^{[12]}$ In addition, heteroleptic gold(I) complexes stabilized by dithiocarbamate and $\mathrm{NHC}$ ligands have shown potent in vitro cytotoxic activities, including towards cisplatin-resistant cancer cells. ${ }^{[13]}$

In this paper, we display a simple procedure for the preparation of $\mathrm{N}$-heterocyclic carbene platinum complexes featuring a dithiocarbamate ligand, using the lability of a trans pyridine ligand in an $\mathrm{N}$-heterocyclic carbene- $\mathrm{Pt}(\mathrm{II})$-pyridine complex (Figure 1). A representative complex could be characterized by $\mathrm{X}$-ray crystallographic studies. Preliminary results of the biological effects on various cancer cells and comparison with cisplatin are also reported.<smiles>[R]N([R4])C1=[SH][P+](I)(C2N([R])C=CN2[R2])S1</smiles>

Figure 1. General molecular structure of the heteroleptic NHC dithiocarbamate platinum complexes.

\section{Results and Discussion}

\section{Synthesis of the NHC Pt complexes}

We used two representative $\mathrm{Pt}$ carbene complexes (NHC) $\mathrm{Ptl}_{2}$ (pyridine) as precursors to access functionalized dithiocarbamate-NHC complexes (Scheme 1). The reaction of $(\mathrm{NHC}) \mathrm{Ptl}_{2}$ (pyridine) complex (1 or 2) with one equivalent of sodium dithiocarbamate in acetonitrile at $60^{\circ} \mathrm{C}$ for 12 hours under 
argon generated the expected complex in yield ranging from $48 \%$ to $80 \%$ after purification on $\mathrm{SiO}_{2}$ chromatography. All complexes were found highly stable in the air both in the solid state and in solution over a period of month (solvent: $\mathrm{CH}_{2} \mathrm{Cl}_{2}$ ). Figure 1 displays the molecular structure of all synthesized complexes. Three achiral dithiocarbamate were used, namely diethyldithiocarbamate, pyrrolidinedithiocarbamate and dibenzyldithiocarbamate. We also extended to more complex sulfur-functionalized building blocks and used two amino esters as models, namely sarcosine and (L)-phenylalanine. The corresponding dithiocarbamates were easily obtained by reaction of the amino ester with $\mathrm{CS}_{2}$ in presence of $\mathrm{NaHCO}_{3}$ in methanol at $0^{\circ} \mathrm{C}$ overnight.

Classical analyses established the formation of the heterotopic complexes. In particular, infrared analyses revealed a C-S bond stretching ranging from 1495 to $1522 \mathrm{~cm}^{-1}$. Regarding the thioureide C-N, the stretching was observed at $1494-1522 \mathrm{~cm}^{-1}$ which is consistent with a partial $\mathrm{C}-\mathrm{N}$ double character compared to free ligand (vc-N of 1474 to $1415 \mathrm{~cm}^{-1}$ for the free ligands). The spectra suggest a bidentate coordination mode of the dithiocarbamate ligand, which was confirmed by X-ray analyses (vide infra).

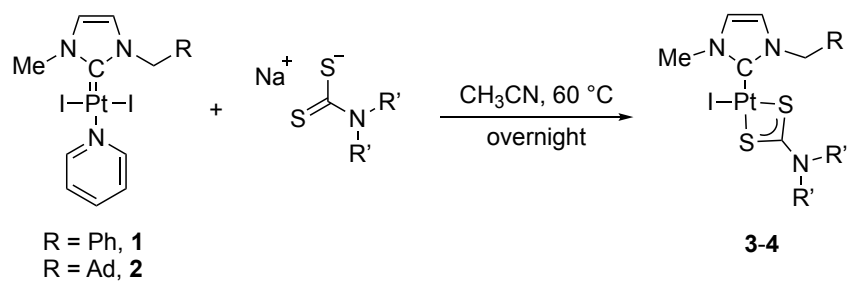

$$
\text { Et }
$$<smiles>[R]CN1C=CN(C)[C@@H]1[In]1SC(N2CCCC2)=[SH]1</smiles>

$$
\begin{aligned}
& -\mathrm{N}^{-}{ }^{-N} v^{R} \\
& 1-P t-S \\
& \mathrm{~S}=\mathrm{f}_{\mathrm{N}-\mathrm{Bn}} \\
& \text { Bn }
\end{aligned}
$$

$$
\begin{array}{llll}
\mathrm{R}=\mathrm{Ph} & \mathbf{3 a}(74 \%) & \text { 3b }(71 \%) & \text { 3c }(69 \%) \\
\mathrm{R}=\mathrm{Ad} & \mathbf{4 a}(55 \%) & \text { 4b }(80 \%) & \text { 4c }(76 \%)
\end{array}
$$

$$
\stackrel{\mathrm{C}}{\mathrm{C}}
$$

$$
\begin{array}{lll}
\mathrm{R}=\mathrm{Ph} & \text { 3d (52\%) } & \text { 3e }(48 \%) \\
\mathrm{R}=\mathrm{Ad} & \text { 4d (52\%) } & \text { 4e (56\%) }
\end{array}
$$

Scheme 1. Pyridine substitution with diverse dithiocarbamates $(\mathrm{Ad}=$ adamantly, $\mathrm{Ph}=$ phenyl).

Suitable crystals of complex $\mathbf{3 a}$ were obtained by slow evaporation of a solution of the compound in dichloromethane. Figure 2 displays the molecular structure along with selected bond distances and angles. The geometry around the metal is pseudo square-planar with the dithiocarbamate acting as a bidentate ligand. The carbene-Pt bond distance is of 2.002(7) $\AA$, which is in agreement with related complexes. ${ }^{14}$ The $\mathrm{NHC}$ ligand plane lies almost perpendicularly toward the square plane [N(2)-C(1)-Pt(1)$\mathrm{S}(1), 82.46^{\circ}$ ] and the iodine ligand points perpendicularly toward the carbene ligand plane $\left[\mathrm{I}(1)-\mathrm{Pt}(1)-\mathrm{C}(1)=90.11^{\circ}\right]$. The Pt-I bond length is of 2.6270(6) $\AA$. The Pt-S bond length for the $S$ atom in trans disposition to the carbene ligand is significantly longer than trans to the iodide atom [2.3641(18) vs. 2.297(2) $\AA$ ], a feature that is consistent with the trans influence of the $\mathrm{NHC}$ ligand.

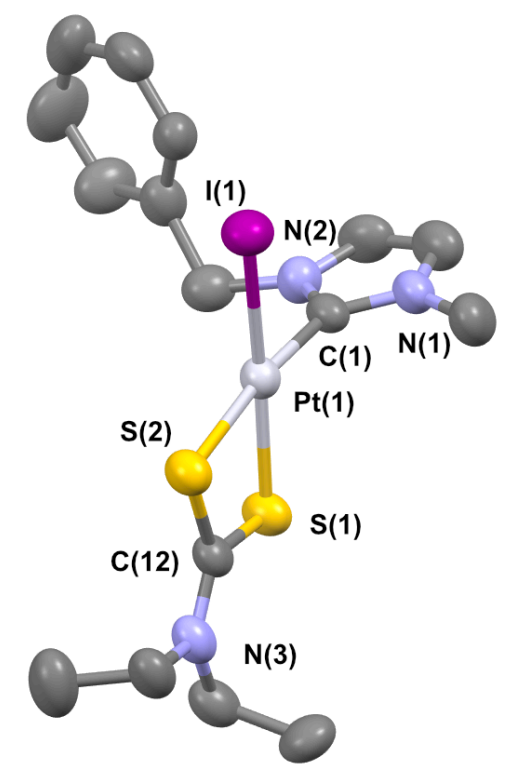

Figure 2. Molecular structure of Pt-NHC complexes 3a. Selected bond distances $(\AA)$ and angles (deg): Pt(1)-C(1), 2.002(7); Pt(1)-I(1), 2.6270(6); Pt(1)$\mathrm{S}(1), 2.297(2) ; \mathrm{Pt}(1)-\mathrm{S}(2), 2.3641(18) ; \mathrm{C}(12)-\mathrm{N}(3), 1.317(9) ; \mathrm{C}(1)-\mathrm{Pt}(1)-\mathrm{I}(1)$, 90.1(2); C(1)-Pt(1)-S(1), 96.9(2); C(1)-Pt(1)-S(2), 171.9(2); S(2)-C(12)-S(1), 110.5(4); N(2)-C(1)-N(1), 105.2(6); N(2)-C(1)-Pt(1)-S(1), 82.5(8); Pt(1)-S(1)$\mathrm{C}(12)-\mathrm{S}(2), 1.7(8)$.

\section{Biological evaluation}

We first evaluated the antitumoral activity of these complexes toward two human cancer cell lines, namely MCF7 breast carcinoma and PC3 prostate adenocarcinoma. The concentrations of these compounds allowing to reduce the cell viability by $50 \%$ (half inhibitory concentrations; $I_{50}$ in $\mu \mathrm{M}$ ) are shown in Table 1. Cisplatin was used as reference for the studies. The Pt carbene complexes ( $\mathrm{NHC}$ ) Ptl 2 (pyridine) (1 or 2) were also evaluated for comparison purpose.

$\mathrm{IC}_{50}$ values for the dithiocarbamate $\mathrm{NHC} \mathrm{Pt}$ complexes are ranging from $0.9 \mu \mathrm{M}$ (4b on MCF7 cells) to $16.9 \mu \mathrm{M}$ (4e on MCF7 cells). Most complexes were found to be more active than Cisplatin, in particular complexes 3c, 3d, and $\mathbf{4 a - d}$. Interestingly, the presence of the methyl adamantane substituent onto the NHC tends to increase the activity of the complexes when compared to benzyl substituents. This effect was particularly seen with compounds $3 a$ versus $\mathbf{4 a}$ and $\mathbf{3 b}$ versus $\mathbf{4 b}$. The $\mathrm{Pt}$ carbene complexes ( $\mathrm{NHC}) \mathrm{Ptl}_{2}$ (pyridine) (1 and 2) also showed good activities ranging from 3.1 to $0.2 \mu \mathrm{M}$. 
Table 1. Half inhibitory concentrations $\mathrm{IC}_{50}$ (in $\mu \mathrm{M}$ ) of the compounds against human cancer cell lines MCF7 and PC3 (after $72 \mathrm{~h}$ of incubation). ${ }^{[a]}$

\begin{tabular}{clllll}
\hline & MCF7 & PC3 & & MCF7 & PC3 \\
\hline Cisplatin & $4.15 \pm 0.07$ & $3.10 \pm 0.20$ & & & \\
3a & $15.66 \pm 3.09$ & $13.13 \pm 2.71$ & $\mathbf{4 a}$ & $1.97 \pm 0.75$ & $0.75 \pm 0.06$ \\
3b & $10.3 \pm 0.09$ & $13.3 \pm 3.44$ & $\mathbf{4 b}$ & $0.91 \pm 0.02$ & $2.22 \pm 0.72$ \\
3c & $2.03 \pm 0.21$ & $1.20 \pm 0.13$ & $\mathbf{4 c}$ & $1.02 \pm 0.03$ & $1.53 \pm 0.08$ \\
3d & $2.29 \pm 0.49$ & $2.10 \pm 0.09$ & $\mathbf{4 d}$ & $2.29 \pm 0.19$ & $2.05 \pm 0.17$ \\
3e & $14.5 \pm 0.48$ & $9.94 \pm 0.42$ & $\mathbf{4 e}$ & $16.9 \pm 0.41$ & $3.32 \pm 0.15$ \\
$\mathbf{1}$ & $0.21 \pm 0.01$ & $0.22 \pm 0.01$ & $\mathbf{2}$ & $3.09 \pm 0.59$ & $0.60 \pm 0.01$ \\
\hline
\end{tabular}

[a] MCF7, breast carcinoma; PC3, prostate adenocarcinoma.

It was shown that metal $\mathrm{NHC}$ complexes as anticancer drugs induced cytotoxicity by altering the activity of various organelles in the cell. ${ }^{[15]}$ Such feature is of particular interest for the treatment of cisplatin-resistant tumours for which DNA lesions are not sufficient to induce cell death. Interestingly, we and others have shown that gold(I) and platinum(II) NHC complexes are also able to alter mitochondria function, and this in turn leads to the induction of apoptosis. Indeed, we recently showed that NHC-Pt$\mathrm{PEI}$ complexes are targeting both nucleus and mitochondria on HCT116 colon carcinoma cells; and this may explain the very superior cell killing activity of the conjugate as compared to cisplatin and oxaliplatin. ${ }^{[16]}$

To gain a better insight into the mechanism of action of the newly synthesized metallodrugs, we performed additional experiments. First, we conducted cell viability assays with a selection of three complexes, namely $\mathbf{2}, \mathbf{4 b}$ and $\mathbf{4 c}$, on HCT116 cancer cell line (for comparison purpose with our previous investigations) ${ }^{[16]}$ As for the two previously studied cell lines, they all displayed significant in vitro cell killing with $\mathrm{IC}_{50}$ of $1.21 \pm 0.06,3.49 \pm 0.05$ and $3.05 \pm$ $0.08 \mu \mathrm{M}$, respectively. Next, we wanted to evaluate whether the cytotoxic activity of these NHC Pt complexes is also correlated with mitochondrial dysfunctions as previously observed with NHC-Pt-PEI. To this end, we performed the following experiments: we measured two parameters 1-production of Reactive Oxygen Species (ROS) in mitochondria and more specially superoxide production, and 2- their respiratory activity after $24 \mathrm{~h}$ cell treatment. We showed that cell death induced by compounds $\mathbf{2}, \mathbf{4 b}$ and $\mathbf{4 c}$ is correlated with the induction of a dose-dependent ROS production and an increased number of cells with inactive mitochondria similar to staurosporine, a compound known to affect ROS production and, thus, used as a reference ${ }^{[17]}$ As results of flow cytometry experiments, Figure 3 displays the percentages of cells that have positively reacted with the MitoSox ${ }^{\mathrm{TM}}$ red mitochondrial superoxide indicator, which is a fluorogenic dye that specifically target mitochondria in live cells and induce red fluorescence under oxidation by superoxide (i.e. ROS production) at concentrations ranging from 0 to $50 \mu \mathrm{M}$. Figure 4 shows the percentages of cells with non-respiratory potential after labelling with MitoTracker Green FM and MitoTracker Deep Red, that allow for detecting and monitoring changes in mitochondria function on imaging and flow cytometry platforms. The three complexes showed a ROS production that is higher than that of the positive control staurosporine. These results are associated with an increased number of cells with nonrespiratory mitochondrial function.

Taken together, these results suggest that dithiocarbamate $\mathrm{NHC}$ $\mathrm{Pt}$ complexes cytotoxicity ensue, at least in part, from mitochondria dysfunction and highlight their potential for further studies. It would in particular be interesting to evaluate in the future these new compounds on cisplatin-resistant tumor cells in order to see whether NHC-Pt mediated mitochondria alteration could overcome the $\mathrm{Pt}$ resistance.

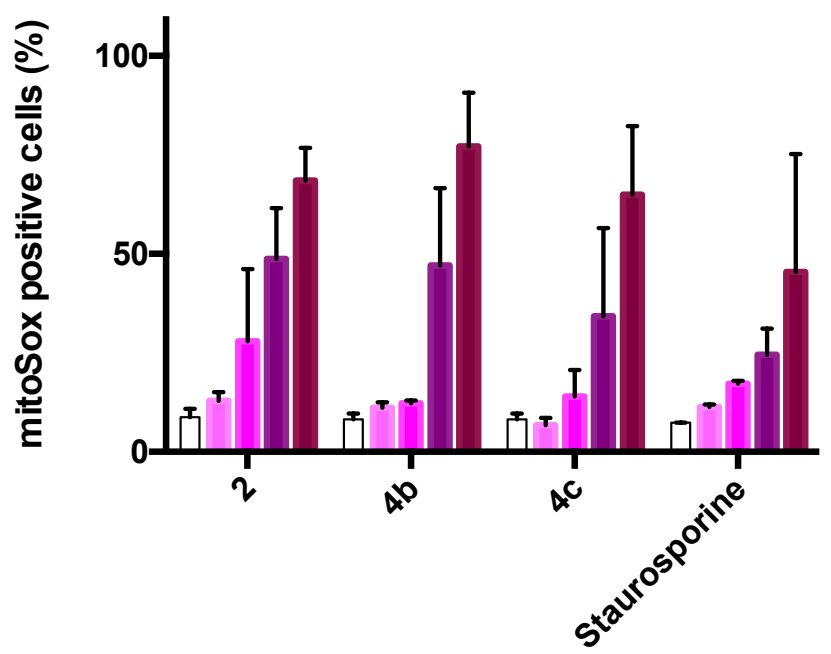

Figure 3. Effects on HCT116 mitochondrial function of $24 \mathrm{~h}$ cell incubation with compounds 2, 4b, 4c and Staurosporine with increased concentration of 0 , $0.8,3.1,12.5$ and $50.0 \mu \mathrm{M}$ (from left to right): percentage of MitoSox positive cells after staining with MitoSox Red mitochondrial superoxide indicator.

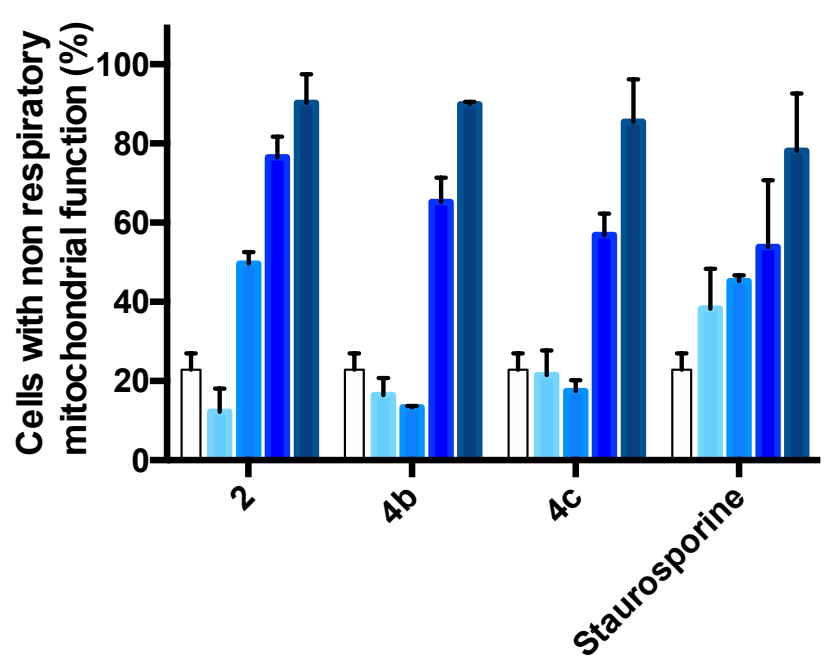

Figure 4. Effects on HCT116 mitochondrial function of $24 \mathrm{~h}$ cell incubation with compounds 2, 4b, 4c and Staurosporine with increased concentration of 0 , $0.8,3.1,12.5$ and $50.0 \mu \mathrm{M}$ (from left to right): percentage of cells with nonrespiratory potential after MitoTracker Green FM and MitoTracker Deep Red. 


\section{Conclusion}

In conclusion, we have synthesized novel platinum(II) $\mathrm{N}$ heterocyclic carbene complexes bearing dithiocarbamate ligands in a simple and straightforward manner. These compounds show high stability in solution and the antiproliferative activity of these complexes was assayed against several cancer cell lines. Preliminary mechanistic investigations revealed that mitochondrial dysfunction and ROS production were correlated with the cytotoxicity induced by these complexes. Further studies will be conducted on the cytotoxicity of the compounds on noncancerous cell lines.

\section{Experimental Section}

Materials and methods. All manipulations were carried out using standard Schlenk techniques unless stated otherwise. Reagents were purchased from commercial chemical suppliers and used without further purification. Solvents were dried according to standard procedures. Metal complexes were synthesized using distilled solvents. The imidazolium precursors were synthesized according to the procedure reported in literature. $\left.{ }^{[3 b, 18}\right]$ The dithiocarbamate were obtained from reported procedure. ${ }^{[19]}{ }^{1} \mathrm{H},{ }^{13} \mathrm{C}$ nuclear magnetic resonance (NMR) spectra were recorded on a Bruker Avance 300 spectrometer. ${ }^{13} \mathrm{C}$ assignments were confirmed when necessary with the use of DEPT-135 experiments. ${ }^{1} \mathrm{H}$ and ${ }^{13} \mathrm{C}-\mathrm{NMR}$ spectra were referenced using the residual solvent peak $\left(\mathrm{CDCl}_{3}\right.$ : $\delta \mathrm{H}=7.26 \mathrm{ppm} ; \delta \mathrm{C}=77.16 \mathrm{ppm} ; \mathrm{CD}_{2} \mathrm{Cl}: 2 \delta \mathrm{H}=5.32 \mathrm{ppm} ; \delta \mathrm{C}=53.84$ ppm; DMSO- $d_{6}: \delta \mathrm{H}=2.50 \mathrm{ppm} ; \delta \mathrm{C}=39.52 \mathrm{ppm}$ ) at $295 \mathrm{~K}$. Chemical shifts $\delta$ are given in ppm whereas coupling constants $\mathrm{J}$ are stated in Hertz $(\mathrm{Hz})$. Positive mode electrospray ionization mass spectra (ESI-MS) were recorded on microTOF, Bruker Daltonics. X-Ray diffraction studies were carried out by Corinne Bailly and Dr Lydia Karmazin at Institut de Chimie $X$-ray Facility of the University of Strasbourg. Crystal data were collected at $173 \mathrm{~K}$ using a MoKa graphite monochromated $(\lambda=0.71073 \AA)$ radiation on a Nonius KappaCCD diffractometer. The structure was solved using direct methods with SHELXS97552 and refined against F2 using the SHELXL97 software. Non-hydrogen atoms were refined anisotropically. Hydrogen atoms were generated according to stereochemistry and refined using a riding model in SHELXL97. CCDC 1992570 contains the supplementary crystallographic data for this paper. These data can be obtained free of charge from The Cambridge Crystallographic Data Centre.

General procedure for the synthesis of the pyridine/NHC platinum complexes 1-2

The imidazolium precursor (1.1 equiv), $\mathrm{PtCl}_{2}$ (1 equiv, $0.75 \mathrm{mmol}$ ), $\mathrm{Nal}$ (10 equiv) and $\mathrm{K}_{2} \mathrm{CO}_{3}$ (10 equiv) were suspended under argon in anhydrous pyridine $(10 \mathrm{~mL})$. The mixture was sonicated during $10 \mathrm{~min}$, heated overnight at $100{ }^{\circ} \mathrm{C}$, then concentrated under reduced pressure, dissolved in $\mathrm{CH}_{2} \mathrm{Cl}_{2}$ and filtered through a celite plug. The residue was purified by a silica gel chromatography affording the complex as a yellow solid. Analytical data for $\mathbf{1}$ were consistent with those reported in literature. ${ }^{[8]}$ Complex 2: $344 \mathrm{mg}(87 \%)$ purified using EtOAc / Cyclohexane (2/8). ${ }^{1} \mathrm{H}$ NMR $\left(400 \mathrm{MHz}\right.$, Chloroform-d) $\delta 1.62-1.76\left(\mathrm{~m}, 6 \mathrm{H}, \mathrm{H}_{\mathrm{Ad}}\right), 1.78(\mathrm{~d}, \mathrm{~J}=2.9$ $\left.\mathrm{Hz}, 6 \mathrm{H}, \mathrm{H}_{\mathrm{Ad}}\right), 2.02-2.08\left(\mathrm{~m}, 3 \mathrm{H}, \mathrm{H}_{\mathrm{Ad}}\right), 4.02\left(\mathrm{~s}, 3 \mathrm{H}, \mathrm{CH}_{3}-\mathrm{N}\right), 4.22(\mathrm{~s}, 2 \mathrm{H}$, $\left.\mathrm{CH}_{2}-\mathrm{N}\right), 6.85\left(\mathrm{~d}, \mathrm{~J}=2.1 \mathrm{~Hz}, 1 \mathrm{H}, \mathrm{CH}_{\mathrm{im}}\right), 6.87\left(\mathrm{~d}, \mathrm{~J}=2.0 \mathrm{~Hz}, 1 \mathrm{H}, \mathrm{CH}_{\mathrm{im}}\right), 7.28$ - $7.37\left(\mathrm{~m}, 2 \mathrm{H}, \mathrm{CH}_{\text {pyr }}\right), 7.68-7.75\left(\mathrm{~m}, 1 \mathrm{H}, \mathrm{CH}_{\text {pyr }}\right), 8.99-9.06(\mathrm{~m}, 2 \mathrm{H}$, $\left.\mathrm{CH}_{\text {pyr }}\right) .{ }^{13} \mathrm{C}$ NMR (101 MHz, $\left.\mathrm{CDCl}_{3}\right) \delta 153.94\left(\mathrm{CH}_{\text {pyr }}\right), 137.47\left(\mathrm{CH}_{\text {pyr }}\right)$, 137.08 (C-Pt), $125.04\left(\mathrm{CH}_{\text {pyr }}\right), 122.53\left(\mathrm{CH}_{\mathrm{im}}\right), 121.79\left(\mathrm{CH}_{\mathrm{im}}\right), 63.68\left(\mathrm{CH}_{2-}\right.$ $\mathrm{N}), 42.07\left(\mathrm{CH}_{2 \mathrm{Ad}}\right), 39.07\left(\mathrm{CH}_{3}-\mathrm{N}\right), 36.86\left(\mathrm{CH}_{2 \mathrm{Ad}}\right), 35.01\left(\mathrm{C}_{\mathrm{Ad}}\right), 28.39$ $\left(\mathrm{CH}_{\text {Ad }}\right.$ ). HRMS (positive ESI) $\mathrm{m} / \mathrm{z}$ [M-l]: calculated for $\mathrm{C}_{20} \mathrm{H}_{27} \mathrm{IN}_{3} \mathrm{Pt}$ 631.0897, found 631.0895. FT-IR $3100\left(\mathrm{C}-\mathrm{H}_{\text {Ar }}\right), 2900\left(\mathrm{C}-\mathrm{H}_{\text {Alk }}\right), 2837(\mathrm{~N}-$ $\left.\mathrm{CH}_{3}\right) \mathrm{cm}^{-1}$.
General procedure for the synthesis of dithiocarbamate NHCplatinum complexes 3-4

Pyridine complex 1 or 2 (1 equiv.) and dithiocarbamate (1 equiv.) was added in a Schlenck under argon and anhydrous acetonitrile was added (ca. $2 \mathrm{~mL} / 0.1 \mathrm{mmol} \mathrm{Pt}$ ). The mixture was heated at $60^{\circ} \mathrm{C}$ overnight, then concentrated under reduced pressure. The residue was purified by a silica gel chromatography (EtOAc/cyclohexane or DCM/pentane).

Compound 3a: Starting from complex 1 (30 mg, $0.043 \mathrm{mmol})$. Yield 20.5 mg (74\%). ${ }^{1} \mathrm{H}$ NMR (400 MHz, Chloroform-d) $\delta 1.24-1.31\left(\mathrm{~m}, 6 \mathrm{H}, \mathrm{CH}_{3}-\right.$ $\mathrm{CH}_{2}$ ), 3.52 (qd, $J=7.1,3.1 \mathrm{~Hz}, 2 \mathrm{H}, \mathrm{CH}_{2}-\mathrm{CH}_{3}$ ), 3.62 (q, $J=7.2 \mathrm{~Hz}, 2 \mathrm{H}$, $\left.\mathrm{CH}_{2}-\mathrm{CH}_{3}\right), 4.02$ (s, 3H, CH $3-\mathrm{N}$ ), 5.66 (d, J = $\left.14.7 \mathrm{~Hz}, 1 \mathrm{H}, \mathrm{CH}_{2}-\mathrm{N}\right), 5.81$ (d, $\left.J=14.8 \mathrm{~Hz}, 1 \mathrm{H}, \mathrm{CH}_{2}-\mathrm{N}\right), 6.66\left(\mathrm{~d}, J=2.1 \mathrm{~Hz}, 1 \mathrm{H}, \mathrm{CH}_{\mathrm{im}}\right), 6.82(\mathrm{~d}, J=2.1$ $\left.\mathrm{Hz}, 1 \mathrm{H}, \mathrm{CH}_{\mathrm{im}}\right), 7.27-7.42\left(\mathrm{~m}, 5 \mathrm{H}, \mathrm{CH}_{\text {arom }}\right)$ ppm. ${ }^{13} \mathrm{C}$ NMR $(101 \mathrm{MHz}$, $\left.\mathrm{CDCl}_{3}\right) \delta 210.06\left(\mathrm{C}-\mathrm{S}_{2}\right), 156.50(\mathrm{C}-\mathrm{Pt}), 136.10$ (Carom), $128.92\left(\mathrm{CH}_{\text {arom }}\right)$, 128.84 ( $\left.\mathrm{CH}_{\text {arom}}\right), 128.29$ ( $\left.\mathrm{CH}_{\text {arom }}\right), 122.37\left(\mathrm{CH}_{\mathrm{im}}\right), 120.07\left(\mathrm{CH}_{\mathrm{im}}\right), 54.61$ $\left(\mathrm{CH}_{2}-\mathrm{N}\right), 43.66\left(\mathrm{CH}_{2}-\mathrm{CH}_{3}\right), 38.42\left(\mathrm{CH}_{3}-\mathrm{N}\right), 12.42\left(\mathrm{CH}_{3}-\mathrm{CH}_{2}\right)$. FTIR: $v$ (pure, diamond orbit): 1515 (C-N) $\mathrm{cm}^{-1}$. HRMS (positive ESI) $\mathrm{m} / \mathrm{z}$ [M-I]: calculated for $\mathrm{C}_{16} \mathrm{H}_{22} \mathrm{~N}_{3} \mathrm{PtS}{ }_{2}$ 515.0903, found 515.0896.

Compound 3b: Starting from complex 1 (40 mg, $0.057 \mathrm{mmol})$. Yield 26.0 mg (71\%). ${ }^{1} \mathrm{H}$ NMR $\left(400 \mathrm{MHz}\right.$, Chloroform-d) $\delta 1.99-2.07\left(\mathrm{~m}, 4 \mathrm{H}, \mathrm{C}_{3} \mathrm{H}_{2}\right)$, $3.60-3.67\left(\mathrm{~m}, 2 \mathrm{H}, \mathrm{C}_{2} \mathrm{H}_{2}-\mathrm{N}\right), 3.68-3.76\left(\mathrm{~m}, 2 \mathrm{H}, \mathrm{C}_{2} \mathrm{H}_{2}-\mathrm{N}\right), 4.02(\mathrm{~s}, 3 \mathrm{H}$, $\mathrm{CH}_{3}-\mathrm{N}$ ), 5.64 (d, $\left.J=14.8 \mathrm{~Hz}, 1 \mathrm{H}, \mathrm{CH}_{2}-\mathrm{N}\right), 5.84\left(\mathrm{~d}, J=14.8 \mathrm{~Hz}, 1 \mathrm{H}, \mathrm{CH}_{2}-\right.$ $\mathrm{N}), 6.66\left(\mathrm{~d}, J=2.0 \mathrm{~Hz}, 1 \mathrm{H}, \mathrm{CH}_{\mathrm{im}}\right), 6.82\left(\mathrm{~d}, J=2.0 \mathrm{~Hz}, 1 \mathrm{H}, \mathrm{CH}_{\mathrm{im}}\right), 7.28-$ $7.43\left(\mathrm{~m}, 5 \mathrm{H}, \mathrm{CH}_{\text {arom}}\right)$ ppm. ${ }^{13} \mathrm{C}$ NMR (101 MHz, CDCl $)$ ठ $205.82\left(\mathrm{C}-\mathrm{S}_{2}\right)$, 155.65 (C-Pt), 136.07 (Carom), $128.93\left(\mathrm{CH}_{\text {arom }}\right), 128.80\left(\mathrm{CH}_{\text {arom }}\right), 128.29$ $\left(\mathrm{CH}_{\text {arom }}\right), 122.39\left(\mathrm{CH}_{\mathrm{im}}\right), 120.05\left(\mathrm{CH}_{\mathrm{im}}\right), 54.58\left(\mathrm{CH}_{2}-\mathrm{N}\right), 48.79\left(\mathrm{CH}_{2}-\mathrm{C}_{2} \mathrm{H}_{2}-\right.$ $\mathrm{N}), 48.47\left(\mathrm{CH}_{2}-\mathrm{C}_{2} \mathrm{H}_{2}-\mathrm{N}\right), 38.37\left(\mathrm{CH}_{3}-\mathrm{N}\right), 24.53\left(\mathrm{CH}_{2}-\mathrm{C}_{3} \mathrm{H}_{2}-\mathrm{CH}_{2}\right), 24.35$ $\left(\mathrm{CH}_{2}-\mathrm{C}_{3} \mathrm{H}_{2}-\mathrm{CH}_{2}\right)$ ppm. FTIR: $v$ (pure, diamond orbit): $1522(\mathrm{C}-\mathrm{N}) \mathrm{cm}^{-1}$. HRMS (positive ESI) $\mathrm{m} / \mathrm{z}$ [M-I]: calculated for $\mathrm{C}_{16} \mathrm{H}_{20} \mathrm{~N}_{3} \mathrm{PtS}_{2}$ 513.0746, found 513.0757 .

Compound 3c: Starting from complex 1 (30 mg, $0.043 \mathrm{mmol})$. Yield 26.5 mg (69\%). ${ }^{1} \mathrm{H}$ NMR (500 MHz, Chloroform-d) $\delta 4.05$ (s, 3H, $\left.\mathrm{CH}_{3}-\mathrm{N}\right), 4.58$ (d, J = 2.4 Hz, 2H, CH $2-\mathrm{N}), 4.69\left(\mathrm{~d}, J=3.4 \mathrm{~Hz}, 2 \mathrm{H}, \mathrm{CH}_{2}-\mathrm{N}\right), 5.65(\mathrm{~d}, J=$ $\left.14.8 \mathrm{~Hz}, 1 \mathrm{H}, \mathrm{CH}_{2}-\mathrm{N}\right), 5.89\left(\mathrm{~d}, J=14.7 \mathrm{~Hz}, 1 \mathrm{H}, \mathrm{CH}_{2}-\mathrm{N}\right), 6.70(\mathrm{~d}, J=2.0 \mathrm{~Hz}$, $\left.1 \mathrm{H}, \mathrm{CH}_{\text {im }}\right), 6.84\left(\mathrm{~d}, J=2.0 \mathrm{~Hz}, 1 \mathrm{H}, \mathrm{CH}_{\text {im }}\right), 7.23-7.26\left(\mathrm{~m}, 2 \mathrm{H}, \mathrm{CH}_{\text {arom }}\right), 7.28$ - $7.44\left(\mathrm{~m}, 13 \mathrm{H}, \mathrm{CH}_{\text {arom }}\right){ }^{13} \mathrm{C}$ NMR $\left(126 \mathrm{MHz}, \mathrm{CDCl}_{3}\right) \delta 213.85\left(\mathrm{C}_{-} \mathrm{S}_{2}\right)$, 155.83 (C-Pt), 136.10 (Carom), 133.83 (C arom), 133.77 ( $\left.\mathrm{C}_{\text {arom}}\right), 129.17$ $\left(\mathrm{CH}_{\text {arom }}\right), 129.13\left(\mathrm{CH}_{\text {arom }}\right), 129.01\left(\mathrm{CH}_{\text {arom }}\right), 128.95\left(\mathrm{CH}_{\text {arom }}\right), 128.80$ $\left(\mathrm{CH}_{\text {arom }}\right), 128.62\left(\mathrm{CH}_{\text {arom }}\right), 128.61\left(\mathrm{CH}_{\text {arom }}\right), 128.43\left(\mathrm{CH}_{\text {arom }}\right), 128.32$ $\left(\mathrm{CH}_{\text {arom }}\right), 122.46\left(\mathrm{CH}_{\mathrm{im}}\right), 120.24\left(\mathrm{CH}_{\mathrm{im}}\right), 54.67\left(\mathrm{CH}_{2}-\mathrm{N}\right), 50.38\left(\mathrm{CH}_{2}-\mathrm{N}\right)$, $50.36\left(\mathrm{CH}_{2}-\mathrm{N}\right), 38.51\left(\mathrm{CH}_{3}-\mathrm{N}\right)$. FTIR: $v$ (pure, diamond orbit): 1494 (C-N) $\mathrm{cm}^{-1}$. HRMS (positive ESI) $\mathrm{m} / \mathrm{z} \quad[\mathrm{M}-\mathrm{I}]$ : calculated for $\mathrm{C}_{26} \mathrm{H}_{26} \mathrm{~N}_{3} \mathrm{PtS} 2639.1216$, found 639.1196.

Compound 3d: Starting from complex 1 (30 mg, $0.043 \mathrm{mmol})$. Yield 16.6 $\mathrm{mg}(52 \%)$ in a $1.7 / 1$ mixture of isomers. ${ }^{1} \mathrm{H}$ NMR $(500 \mathrm{MHz}$, Chloroform-d) ס $7.42-7.26\left(\mathrm{~m}, 13.83 \mathrm{H}, \mathrm{CH}_{\text {arom }}\right), 7.18(\mathrm{br}, 1.6 \mathrm{H}, \mathrm{NH}$ Major + minor $), 7.12-$ $7.05\left(\mathrm{~m}, 3.5 \mathrm{H}, \mathrm{CH}_{\text {arom }}\right), 6.86-6.82\left(\mathrm{~m}, 1.7 \mathrm{H}, \mathrm{CH}_{\text {im Major + minor }), 6.71-6.75}\right.$

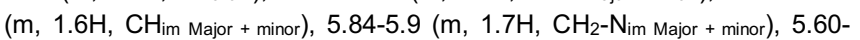
$5.068\left(\mathrm{~m}, 1.6 \mathrm{H}, \mathrm{CH}_{2}-\mathrm{Nim}\right.$ Major + minor), 5.10 (br, 1H, CH-NH Major), 4.89 (dd, J $=13.0,5.5 \mathrm{~Hz}, 0.7 \mathrm{H}, \mathrm{CH}-\mathrm{NH}$ minor), 4.02-4.07 (m, 5.2, $\mathrm{CH}_{3}-\mathrm{N}$ Major + minor), $3.74\left(\mathrm{~m}, 5.2 \mathrm{H}, \mathrm{CH}_{3}-\mathrm{O}\right.$ Major + minor), $3.38-3.15\left(\mathrm{~m}, 3.5 \mathrm{H}, \mathrm{CH}_{2 \text { phenylalanine Major }}\right.$ + minor). ppm. ${ }^{13} \mathrm{C}$ NMR (126 MHz, CDCl 3 ) 215.3 (C-S 2 , minor), 214.7 (C-S Major); 169.77 ( $\mathrm{C}=\mathrm{O}, \mathrm{d}, \mathrm{J}=5.0 \mathrm{~Hz}$, Major), 169.24 ( $\mathrm{C}=\mathrm{O}, \mathrm{d}, J=5.1 \mathrm{~Hz}$, minor), 153.85 (C-Pt, d, $J=4.9 \mathrm{~Hz}$, minor), 153.47 (C-Pt, d, $J=2.2 \mathrm{~Hz}$, Major), 134.97 (Carom, d, $J=11 \mathrm{~Hz}$, minor), 134.94 (Carom, d, $J=7.7 \mathrm{~Hz}$, Major), 134.54 ( $\mathrm{C}_{\text {arom, }}$

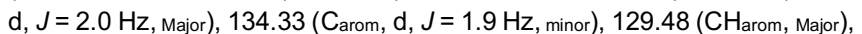
129.45 ( $\left.\mathrm{CH}_{\text {arom, minor }}\right), 129.05$ ( $\mathrm{CH}_{\text {arom }} \mathrm{d}, J=2.2 \mathrm{~Hz}$, minor $), 128.97\left(\mathrm{CH}_{\text {arom, }}\right.$ d $J=2.4 \mathrm{~Hz}$, Major $) 128.81,128.75$ and $128.70\left(\mathrm{CH}_{\text {arom, Major }+ \text { minor }), 128.39}\right.$ ( $\left.\mathrm{CH}_{\text {arom, Major }}\right), 128.38$ ( $\left.\mathrm{CH}_{\text {arom, minor }}\right), 127.85$ ( $\mathrm{CH}_{\text {arom }}, \mathrm{d}, J=1.2 \mathrm{~Hz}$, minor $)$, $127.74\left(\mathrm{CH}_{\text {arom }}, \mathrm{d}, J=2.4 \mathrm{~Hz}\right.$, Major $), 120.52\left(\mathrm{CH}_{\mathrm{im}}\right.$, Major $), 120.47\left(\mathrm{CH}_{\mathrm{im}}\right.$, minor $), 120.28-120.40\left(\mathrm{CH}_{\mathrm{im}}, \mathrm{m}\right.$, minor + Major $), 55.81(\mathrm{CH}-\mathrm{NH}$, minor $), 55.63(\mathrm{CH}-$ $\mathrm{NH}$, Major $)$, 54.64-54.70 $\left(\mathrm{CH}_{2}-\mathrm{N}\right.$, minor + Major $) 53.07\left(\mathrm{CH}_{3}-\mathrm{O}, \mathrm{d}, \mathrm{J}=2.6 \mathrm{~Hz}\right.$, minor), $53.04\left(\mathrm{CH}_{3}-\mathrm{O}, \mathrm{d}, J=0.6 \mathrm{~Hz}\right.$, Major $), 38.49\left(\mathrm{CH}_{3}-\mathrm{N}, \mathrm{d}, J=9.7 \mathrm{~Hz}\right.$, Major $)$, 
$38.46\left(\mathrm{CH}_{3}-\mathrm{N}, \mathrm{d}, J=2.9 \mathrm{~Hz}\right.$, minor $), 37.96\left(\mathrm{CH}_{2}-\mathrm{CHN}, \mathrm{d}, J=7.4 \mathrm{~Hz}\right.$, minor $)$, $37.68\left(\mathrm{CH}_{2}-\mathrm{CHN}, \mathrm{d}, J=5.3 \mathrm{~Hz}\right.$, Major $)$ ppm. FTIR: $v$ (pure, diamond orbit):

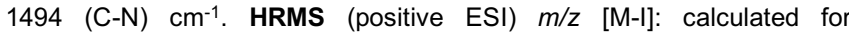
$\mathrm{C}_{22} \mathrm{H}_{24} \mathrm{~N}_{3} \mathrm{O}_{2} \mathrm{PtS}_{2}$ 621.0958, found 621.0937

Compound 3e: Starting from complex 1 (40 mg, $0.057 \mathrm{mmol}$ ). Yield 22.4 $\mathrm{mg}(58 \%)$ in a $1.5 / 1$ mixture of isomer. ${ }^{1} \mathbf{H}$ NMR $(300 \mathrm{MHz}$, Chloroform-d)

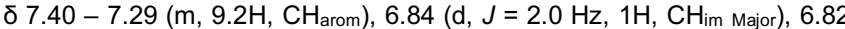

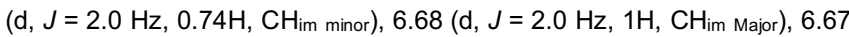

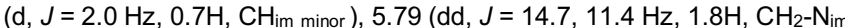

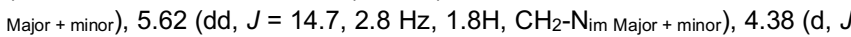
$=17.5 \mathrm{~Hz}, 1 \mathrm{H}, \mathrm{CH}_{2}-\mathrm{NMe}$, Major), $4.33\left(\mathrm{~d}, J=17.5 \mathrm{~Hz}, 1 \mathrm{H}, \mathrm{CH}_{2}-\mathrm{NMe}\right.$, Major), 4.29 (d, $J=17.5 \mathrm{~Hz}, 0.8 \mathrm{H}, \mathrm{CH}_{2}-\mathrm{NMe}$, minor), 4.20 (d, $J=17.5 \mathrm{~Hz}, 0.8 \mathrm{H}$,

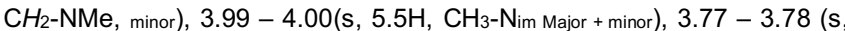
$5.6 \mathrm{H}, \mathrm{CH}_{3}-\mathrm{O}$, Major + minor), 3.26 (s, $2.5 \mathrm{H}, \mathrm{CH}_{3}-\mathrm{N}$ minor), 3.21 (s, $3 \mathrm{H}, \mathrm{CH}_{3}-\mathrm{N}$ Major) ppm.) ppm. ${ }^{13} \mathrm{C}$ NMR (126 MHz, $\left.\mathrm{CDCl}_{3}\right) \delta 215.50$ (C-S 2 , Major), 215.42 (C-S 2 , minor), 167.01 (C=O, Major), 166.92 (C=O, minor), 154.96 (C-Pt, Major),

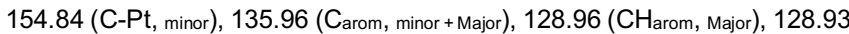

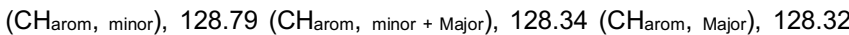
( $\left.\mathrm{CH}_{\text {arom, minor }}\right), 122.48$ ( $\left.\mathrm{CH}_{\text {imid, Major }}\right), 122.45\left(\mathrm{CH}_{\text {im, minor }}\right), 120.20\left(\mathrm{CH}_{\text {im, minor }}\right.$ + Major $), 54.63\left(\mathrm{CH}_{2} \mathrm{~N}_{\text {im }}\right.$, minor $), 54.60\left(\mathrm{CH}_{2} \mathrm{~N}_{\text {im }}\right.$, Major $), 52.97\left(\mathrm{CH}_{3}-\mathrm{O}\right.$, minor $)$, $52.96\left(\mathrm{CH}_{3}-\mathrm{O}\right.$, Major $), 50.90$ ( $\mathrm{CH}_{2}-\mathrm{NMe}$, minor $), 50.70\left(\mathrm{CH}_{2}-\mathrm{NMe}\right.$, Major $), 38.41$ $\left(\mathrm{CH}_{3}-\mathrm{Nim}\right.$, minor + Major $), 37.51\left(\mathrm{CH}_{3}-\mathrm{N}\right.$, minor $), 37.32\left(\mathrm{CH}_{3}-\mathrm{N}\right.$, Major $)$ ppm. FTIR: $v$ (pure, diamond orbit): $1514(\mathrm{C}-\mathrm{N}) \mathrm{cm}^{-1}$. HRMS (positive ESI) $\mathrm{m} / \mathrm{z}$ [M-I]: calculated for $\mathrm{C}_{16} \mathrm{H}_{20} \mathrm{~N}_{3} \mathrm{O}_{2} \mathrm{PtS}_{2}$ 545.0645, found 545.0652 .

Compound 4a: Starting from complex 2 (40 mg, $0.053 \mathrm{mmol})$. Yield 20.4 mg (55\%). ${ }^{1} \mathrm{H}$ NMR (500 MHz, Chloroform-d) $\delta 1.28$ (dt, $J=15.5,7.2 \mathrm{~Hz}$, $\left.6 \mathrm{H}, \mathrm{CH}_{3}-\mathrm{CH}_{2}\right), 1.61-1.77\left(\mathrm{~m}, 13 \mathrm{H}, \mathrm{H}_{\mathrm{Ad}}\right), 2.00\left(\mathrm{p}, J=3.1 \mathrm{~Hz}, 3 \mathrm{H}, \mathrm{H}_{\mathrm{Ad}}\right)$, 3.51 (qd, $\left.J=7.2,1.3 \mathrm{~Hz}, 2 \mathrm{H}, \mathrm{CH}_{2}-\mathrm{CH}_{3}\right), 3.54-3.70\left(\mathrm{~m}, 2 \mathrm{H}, \mathrm{CH}_{2}-\mathrm{CH}_{3}\right.$ ), $3.85\left(\mathrm{~d}, J=13.9 \mathrm{~Hz}, 1 \mathrm{H}, \mathrm{CH}_{2}-\mathrm{N}\right), 4.02\left(\mathrm{~s}, 3 \mathrm{H}, \mathrm{CH}_{3}-\mathrm{N}\right), 4.48$ (d, J = 13.9 $\left.\mathrm{Hz}, 1 \mathrm{H}, \mathrm{CH}_{2}-\mathrm{N}\right), 6.81$ (d, $\left.J=2.0 \mathrm{~Hz}, 1 \mathrm{H}, \mathrm{CH}_{\mathrm{im}}\right), 6.83(\mathrm{~d}, J=2.0 \mathrm{~Hz}, 1 \mathrm{H}$,

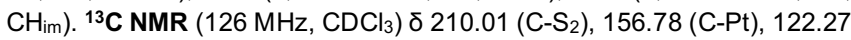
$\left(\mathrm{CH}_{\mathrm{im}}\right), 121.30\left(\mathrm{CH}_{\mathrm{im}}\right), 62.77\left(\mathrm{CH}_{2}-\mathrm{N}\right), 43.56\left(\mathrm{CH}_{2}-\mathrm{CH}_{3}\right), 43.53\left(\mathrm{CH}_{2}-\mathrm{CH}_{3}\right)$, $41.29\left(\mathrm{CH}_{2 \mathrm{Ad}}\right), 38.59\left(\mathrm{CH}_{3}-\mathrm{N}\right), 36.86\left(\mathrm{CH}_{2 \mathrm{Ad}}\right), 34.80\left(\mathrm{C}_{\mathrm{Ad}}\right), 28.44\left(\mathrm{CH}_{\mathrm{Ad}}\right)$, $12.47\left(\mathrm{CH}_{3}-\mathrm{CH}_{2}\right), 12.46\left(\mathrm{CH}_{3}-\mathrm{CH}_{2}\right)$. FTIR: $v$ (pure, diamond orbit): 1514 (C-N) $\mathrm{cm}^{-1}$. HRMS (positive ESI) $\mathrm{m} / \mathrm{z}$ [M-I]: calculated for $\mathrm{C}_{20} \mathrm{H}_{32} \mathrm{~N}_{3} \mathrm{PtS}_{2}$ 573.1685, found 573.1686.

Compound 4b: Starting from complex 2 (40 mg, $0.053 \mathrm{mmol})$. Yield 29.7 $\mathrm{mg}(80 \%) .{ }^{1} \mathrm{H}$ NMR $(500 \mathrm{MHz}$, Chloroform-d $) \delta 1.59-1.65\left(\mathrm{~m}, 6 \mathrm{H}, \mathrm{H}_{\mathrm{Ad}}\right)$, $1.66-1.76\left(\mathrm{~m}, 9 \mathrm{H}, \mathrm{H}_{\mathrm{Ad}} 2.00\left(\mathrm{p}, J=3.1 \mathrm{~Hz}, 2 \mathrm{H}, \mathrm{H}_{\mathrm{Ad}}\right), 2.02-2.08(\mathrm{~m}, 4 \mathrm{H}\right.$, $\left.\mathrm{C}_{3} \mathrm{H}_{2}-\mathrm{CH}_{2}\right), 3.58-3.65\left(\mathrm{~m}, 2 \mathrm{H}, \mathrm{C}_{2} \mathrm{H}_{2}-\mathrm{CH}_{2}\right), 3.68-3.75\left(\mathrm{~m}, 2 \mathrm{H}, \mathrm{C}_{2} \mathrm{H}_{2}-\mathrm{CH}_{2}\right)$, $3.84\left(\mathrm{~d}, J=13.9 \mathrm{~Hz}, 1 \mathrm{H}, \mathrm{CH}_{2}-\mathrm{N}\right), 4.02\left(\mathrm{~s}, 3 \mathrm{H}, \mathrm{CH}_{3}-\mathrm{N}\right), 4.48$ (d, J = 13.9 $\mathrm{Hz}, 1 \mathrm{H}, \mathrm{CH}_{2}-\mathrm{N}$ ), 6.80 (d, $\left.J=2.0 \mathrm{~Hz}, 1 \mathrm{H}, \mathrm{CH}_{\mathrm{im}}\right), 6.83(\mathrm{~d}, J=2.0 \mathrm{~Hz}, 1 \mathrm{H}$, $\left.\mathrm{CH}_{\text {im }}\right){ }^{13} \mathrm{C}$ NMR $\left(126 \mathrm{MHz}, \mathrm{CDCl}_{3}\right) \delta 205.81\left(\mathrm{C}-\mathrm{S}_{2}\right), 155.91(\mathrm{C}-\mathrm{Pt}), 122.28$ $\left(\mathrm{CH}_{\mathrm{im}}\right), 121.29\left(\mathrm{CH}_{\mathrm{im}}\right), 62.80\left(\mathrm{CH}_{2}-\mathrm{N}\right), 48.65\left(\mathrm{C}_{2} \mathrm{H}_{2}\right), 48.34\left(\mathrm{C}_{2} \mathrm{H}_{2}\right), 41.28$ $\left(\mathrm{CH}_{2 \mathrm{Ad}}\right), 38.53\left(\mathrm{CH}_{3}-\mathrm{N}\right), 36.84\left(\mathrm{CH}_{2 \mathrm{Ad}}\right), 34.78\left(\mathrm{C}_{\mathrm{Ad}}\right), 28.40\left(\mathrm{CH}_{\mathrm{Ad}}\right), 24.51$ $\left(\mathrm{C}_{3} \mathrm{H}_{2}\right), 24.33\left(\mathrm{C}_{3} \mathrm{H}_{2}\right)$. FTIR: $v$ (pure, diamond orbit): $1510(\mathrm{C}-\mathrm{N}) \mathrm{cm}^{-1}$. HRMS (positive ESI) $\mathrm{m} / \mathrm{z}$ [M-I]: calculated for $\mathrm{C}_{20} \mathrm{H}_{30} \mathrm{~N}_{3} \mathrm{PtS}_{2}$ 571.1529, found 571.1533

Compound 4c: Starting from complex 2 (30 mg, $0.040 \mathrm{mmol})$. Yield 24.6 $\mathrm{mg}(76 \%)$. ${ }^{1} \mathrm{H}$ NMR ${ }^{1} \mathrm{H}$ NMR $(500 \mathrm{MHz}$, Chloroform- $d) \delta 1.60-1.98(\mathrm{~m}$, $\left.15 \mathrm{H}, \mathrm{H}_{\mathrm{Ad}}\right), 3.79$ (d, J = $\left.13.9 \mathrm{~Hz}, 1 \mathrm{H}, \mathrm{CH}_{2}-\mathrm{N}_{\mathrm{m}}\right), 4.06\left(\mathrm{~s}, 3 \mathrm{H}, \mathrm{CH}_{3}-\mathrm{N}\right), 4.42$ (d, J $=15.2 \mathrm{~Hz}, 1 \mathrm{H}, \mathrm{CH}_{2}-\mathrm{N}$ ), 4.51 (d, J = $14.9 \mathrm{~Hz}, 1 \mathrm{H}, \mathrm{CH}_{2}-\mathrm{N}$ ), 4.65 (d, J = $\left.13.9 \mathrm{~Hz}, 1 \mathrm{H}, \mathrm{CH}_{2}-\mathrm{N}_{\mathrm{im}}\right), 4.73\left(\mathrm{~d}, J=15.2 \mathrm{~Hz}, 1 \mathrm{H}, \mathrm{CH}_{2}-\mathrm{N}\right), 4.86(\mathrm{~d}, J=14.9$ $\left.\mathrm{Hz}, 1 \mathrm{H}, \mathrm{CH}_{2}-\mathrm{N}\right), 6.81-6.89\left(\mathrm{~m}, 2 \mathrm{H}, \mathrm{CH}_{\mathrm{im}}\right), 7.30-7.41(\mathrm{~m}, 10 \mathrm{H}) .{ }^{13} \mathrm{C}$ NMR

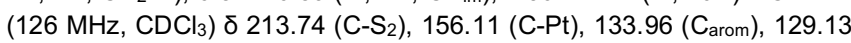
$\left(\mathrm{CH}_{\text {arom }}\right), 129.09\left(\mathrm{CH}_{\text {arom }}\right), 128.60\left(\mathrm{CH}_{\text {arom }}\right), 128.58\left(\mathrm{CH}_{\text {arom }}\right), 128.42$ $\left(\mathrm{CH}_{\text {arom }}\right), 122.42\left(\mathrm{CH}_{\mathrm{im}}\right), 121.38\left(\mathrm{CH}_{\mathrm{im}}\right), 62.88\left(\mathrm{CH}_{2}-\mathrm{N}\right.$ im $), 50.34\left(\mathrm{CH}_{2}-\mathrm{N}\right)$, $50.25\left(\mathrm{CH}_{2}-\mathrm{N}\right), 41.34\left(\mathrm{CH}_{2 \mathrm{Ad}}\right), 38.58\left(\mathrm{CH}_{3}-\mathrm{N}\right), 36.89\left(\mathrm{CH}_{2 \mathrm{Ad}}\right), 34.83\left(\mathrm{C}_{\mathrm{Ad}}\right)$, $28.47\left(\mathrm{CH}_{\text {Ad }}\right)$. FTIR: $v$ (pure, diamond orbit): $1502(\mathrm{C}-\mathrm{N}) \mathrm{cm}^{-1}$. HRMS (positive ESI) $\mathrm{m} / \mathrm{z}$ [M-I]: calculated for $\mathrm{C}_{30} \mathrm{H}_{36} \mathrm{~N}_{3} \mathrm{PtS}{ }_{2}$ 697.1998, found 697.1984.

Compound 4d: Starting from complex 2 (30 mg, $0.040 \mathrm{mmol})$. Yield 18.1 $\mathrm{mg}(57 \%)$ in a $1.3 / 1$ mixture of isomers. ${ }^{1} \mathrm{H}$ NMR $(500 \mathrm{MHz}$, Chloroform- $d)$ $\delta 7.34-7.27(\mathrm{~m}, 1 \mathrm{H}), 7.23-7.06(\mathrm{~m}, 1 \mathrm{H}), 6.84$ (ddd, $J=5.9,3.5,1.7 \mathrm{~Hz}$, $1 \mathrm{H}), 5.10-5.04(\mathrm{~m}, 1 \mathrm{H}, \mathrm{CH}-\mathrm{N}$ major $), 4.93-4.85(\mathrm{~m}, 0.6 \mathrm{H}, \mathrm{CH}-\mathrm{N}$ minor), 4.51-4.62 (m, 1.6, $\mathrm{CH}_{2}-\mathrm{Nim}$, Major + minor), 4.53 (dd, $\left.J=13.9,9.6 \mathrm{~Hz}, 1 \mathrm{H}\right)$,

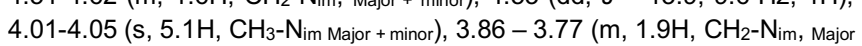
+ minor), $3.78-3.76\left(\mathrm{~m}, 5.1 \mathrm{H}, \mathrm{CH}_{3}-\mathrm{O}\right.$ Major + minor $), 3.46-3.17\left(\mathrm{~m}, 3.5 \mathrm{H}, \mathrm{CH}_{2}\right.$

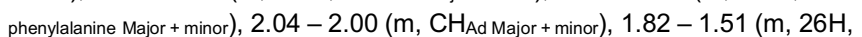

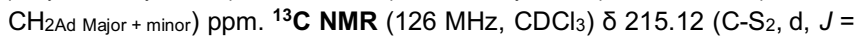
10.6 Hz, minor), 214.46 (C-S $2, d, J=8.6 \mathrm{~Hz}$, Major), 169.88 (C=O, d, $J=1.7$ $\mathrm{Hz}$, , Major), 169.32 (C=O, d, J = 3.5 Hz, minor), 154.11 (C-Pt, d, J = 3.3 Hz, minor), 153.77 (C-Pt, d, $J=1.2 \mathrm{~Hz}$, Major), 134.63 (Carom, $\mathrm{d}, J=1.6 \mathrm{~Hz}$, Major), 134.40 (Carom, d, $J=2.3 \mathrm{~Hz}$, minor), 129.50 ( $\mathrm{CH}_{\text {arom, }} \mathrm{d}, J=2.1 \mathrm{~Hz}$, Major), $129.44\left(\mathrm{CH}_{\text {arom }}, \mathrm{d}, J=11.1 \mathrm{~Hz}\right.$, minor $), 129.03\left(\mathrm{CH}_{\text {arom }}, \mathrm{d}, J=1.3 \mathrm{~Hz}\right.$, minor $)$, $128.91\left(\mathrm{CH}_{\text {arom }}, \mathrm{d}, J=4.1 \mathrm{~Hz}\right.$, Major $), 127.83\left(\mathrm{CH}_{\text {arom }}, \mathrm{d}, J=4.5 \mathrm{~Hz}\right.$, minor $)$,

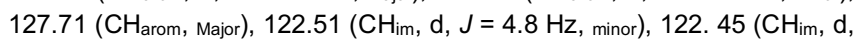
$J=1.6 \mathrm{~Hz}$, Major $), 121.45\left(\mathrm{CH}_{\mathrm{im}}\right.$, minor + Major $), 62.95\left(\mathrm{NCH}_{2}\right.$, minor $), 62.93$ ( $\mathrm{NCH}_{2}$, Major), $55.78(\mathrm{CH}-\mathrm{NH}, \mathrm{d}, J=3.3 \mathrm{~Hz}$, minor), $55.54(\mathrm{CH}-\mathrm{NH}, \mathrm{d}, J=3.3$ $\mathrm{Hz}$, Major), $53.05\left(\mathrm{CH}_{3}-\mathrm{O}, \mathrm{d}, J=8.7 \mathrm{~Hz}\right.$, minor $), 53.02\left(\mathrm{CH}_{3}-\mathrm{O}, \mathrm{d}, J=5.0 \mathrm{~Hz}\right.$, Major), 41.37 and $41.21\left(\mathrm{CH}_{2 \mathrm{Ad}}\right.$, minor + Major), $38.59\left(\mathrm{CH}_{3}-\mathrm{N}, \mathrm{d}, J=16.4 \mathrm{~Hz}\right.$, Major), $38.55\left(\mathrm{CH}_{3}-\mathrm{N}, \mathrm{d}, J=12.1 \mathrm{~Hz}\right.$, minor $), 37.81(\mathrm{CH}-\mathrm{NH}, \mathrm{d}, J=38.1 \mathrm{~Hz}$, minor), $37.68(\mathrm{CH}-\mathrm{NH}, \mathrm{d}, J=33.8 \mathrm{~Hz}$, Major $), 36.88,36,85$ and $36.83\left(\mathrm{CH}_{2 \mathrm{Ad}}\right.$, minor + Major $), 34.81$ and $34.79\left(\mathrm{C}_{\mathrm{Ad}}\right.$, minor + Major $), 28.46$ and $28.39\left(\mathrm{CH}_{\mathrm{Ad}}\right.$, minor + Major) ppm. FTIR: $v$ (pure, diamond orbit): 1497 (C-N) $\mathrm{cm}^{-1}$. HRMS (positive ESI) $\mathrm{m} / \mathrm{z}$ [M-I]: calculated for $\mathrm{C}_{26} \mathrm{H}_{34} \mathrm{~N}_{3} \mathrm{O}_{2} \mathrm{PtS}_{2} 679.1740$, found 679.1728.

Compound 4e: Starting from complex 2 (30 mg, $0.040 \mathrm{mmol})$. Yield 12.6 $\mathrm{mg}(43 \%)$ in a $1.1 / 1$ mixture of isomer. ${ }^{1} \mathbf{H}$ NMR $(500 \mathrm{MHz}$, Chloroform-d)

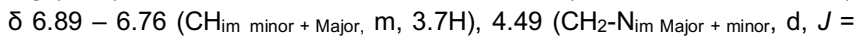
$13.8 \mathrm{~Hz}, 1.79 \mathrm{H}), 4.42\left(\mathrm{CH}_{2}-\mathrm{NMe}\right.$ minor, $\left.\mathrm{d}, \mathrm{J}=17.4 \mathrm{~Hz}, 1 \mathrm{H}\right), 4.29\left(\mathrm{CH}_{2}-\mathrm{NMe}\right.$ Major, $\mathrm{d}, J=17.8 \mathrm{~Hz}, 1.86 \mathrm{H}), 4.18\left(\mathrm{CH}_{2}-\mathrm{NMe}\right.$ minor, $\left.\mathrm{d}, J=17.5 \mathrm{~Hz}, 0.9 \mathrm{H}\right)$, $4.01\left(\mathrm{CH}_{3}-\mathrm{N}\right.$ minor + Major, $\left.\mathrm{m}, 5.65 \mathrm{H}\right), 377-3.83\left(\mathrm{CH}_{3}-\mathrm{O}\right.$ Major + minor and $\mathrm{CH}_{2}-$ $\mathrm{N}$ im Major + minor, m, $7.5 \mathrm{H}), 3.26\left(\mathrm{CH}_{3}\right.$ minor, s, $\left.2.66 \mathrm{H}\right), 3.20\left(\mathrm{CH}_{3}\right.$ Major $\left.\mathrm{s}, 3 \mathrm{H}\right)$,

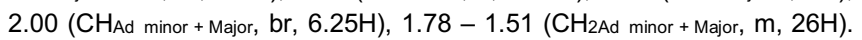
${ }^{13} \mathrm{C}$ NMR (126 MHz, CDCl 3 ) $\delta 215.42\left(\mathrm{C}-\mathrm{S}_{2}, \mathrm{Major}\right), 215.34$ (C-S 2 , minor), 167.14 ( $\mathrm{C}=\mathrm{O}$, minor), 166.99 ( $\mathrm{C}=\mathrm{O}$, Major), 155.27 (C-Pt, Major), 155.15 (C-Pt,

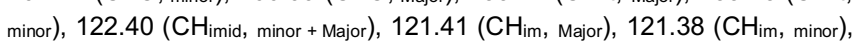
$62.86\left(\mathrm{CH}_{2}-\mathrm{N}\right.$, Major $), 62.84\left(\mathrm{CH}_{2}-\mathrm{N}\right.$, minor $), 52.93\left(\mathrm{CH}_{3}-\mathrm{O}\right.$, Major $), 52.89\left(\mathrm{CH}_{3}-\right.$ $\mathrm{O}$, minor $), 50.57$ ( $\mathrm{CH}_{2}-\mathrm{NMe}$, minor $), 50.57\left(\mathrm{CH}_{2}-\mathrm{NMe}\right.$, Major $), 41.28\left(\mathrm{CH}_{2 \mathrm{Ad}}\right.$, minor $), 41.26\left(\mathrm{CH}_{2 \mathrm{Ad}}\right.$, Major $), 38.57\left(\mathrm{CH}_{3}-\mathrm{N}_{\mathrm{im}}\right.$, Major $), 38.56\left(\mathrm{CH}_{3}-\mathrm{N}_{\mathrm{im}}\right.$, minor $)$, $37.43 \mathrm{CH}_{3}-\mathrm{N}$, Major $), 37.22\left(\mathrm{CH}_{3}-\mathrm{N}\right.$, minor $), 36.83\left(\mathrm{CH}_{2 \mathrm{Ad}}\right.$, minor + Major $), 34.79$ ( $\mathrm{C}_{\mathrm{Ad}}$, Major), 34.77 ( $\mathrm{C}_{\mathrm{Ad}}$, minor $), 28.40\left(\mathrm{CH}_{\mathrm{Ad}}\right.$, minor + Major $)$ ppm. FTIR: $v$ (pure, diamond orbit): 1497 (C-N) $\mathrm{cm}^{-1}$. HRMS (positive ESI) $\mathrm{m} / \mathrm{z}$ [M-I]: calculated for $\mathrm{C}_{20} \mathrm{H}_{30} \mathrm{~N}_{3} \mathrm{O}_{2} \mathrm{PtS} 2603.1427$, found 603.1413.

Cell culture. MCF7 (breast), PC3 (prostate) and HCT116 (colorectal) adenocarcinoma cell lines were cultured in RPMI medium suplemented by $10 \%$ FBS at $37 \circ \mathrm{C}$ with $5 \% \mathrm{CO} 2,95 \%$ humidity.

Cytotoxicity test. Compounds were dissolved in DMSO (except for cisplatin that was dissolved in water) at stock concentrations of 10 $\mathrm{mM}$. Cells were seeded in 96-well plates in $200 \mu \mathrm{l}$ complete medium at a density of 1000-2500 cells per well and treated $24 \mathrm{~h}$ later with 2 $\mu \mathrm{L}$ of compounds to a final concentration ranging from $5 \mathrm{nM}$ to 100 $\mu \mathrm{M}$ using a Biomek 3000 automation workstation (Beckman-Coulter). After $24 \mathrm{~h}$ or $72 \mathrm{~h}$ exposure, MTS reagent (CellTiter $96^{\circledR}$ Aqueous One, Promega) was added and incubated for $3 \mathrm{~h}$ at $37^{\circ} \mathrm{C}$ : the absorbance was monitored at $490 \mathrm{~nm}$ and results expressed as the inhibition of cell proliferation calculated as the ratio [(1-(OD490 treated/OD490 control)) $\times$ 100].

Mitochondrial dysfunction analysis by flow cytometry. The effects of platinum compounds on superoxide production and mitochondrial respiratory activity were evaluated. For this, cells were seeded in 96-well plates at 15000 cells per well in $50 \mu \mathrm{L}$ of complete medium. 24 hours after, $50 \mu \mathrm{L}$ of the different platinum compounds diluted in complete medium were added to the cells for $24 \mathrm{~h}$ at $37 \circ \mathrm{C}$ $\left(5 \% \mathrm{CO}_{2}\right)$. Cells were harvested and then, incubated with either MitoSox Red mitochondrial superoxide indicator (1 $\mu \mathrm{M}$, Invitrogen) or 
with MitoTracker Green FM and MitoTracker Deep Red $633(0.2 \mu \mathrm{M}$ Invitrogen) in the dark for 20 minutes. MitoSox Red is an indicator for superoxide production. The carbocyanine-based MitoTracker dyes allow distinguishing between mitochondria with respiratory activity and mitochondria with non-respiratory activity. Five thousand cells were acquired for each experimental condition using a FacsCalibur (Becton Dickinson) flow cytometer and the Cell Quest Pro Software. The results were processed with FlowJo Data Analysis Software.

[1] B. Rosenberg, L. VanCamp, T. Krigas, Nature 1965, 205, 698

[2] Martindale: The complete drug reference, ed. S. C. Sweetman, Pharmaceutical Press, London, 35th edn, 2007.

[3] a) D. Bourissou, O. Guerret, F. P. Gabbai, G. Bertrand, Chem. Rev. 2009, 253, 862-89; b) For the synthesis of carbene precursors, see: L. Benhamou, E. Chardon, G. Lavigne, S. Bellemin-Laponnaz V. César, Chem. Rev. 2011, 111, 2705.

[4] a) S. Bellemin-Laponnaz, S. Dagorne, Chem. Rev. 2014, 114, 87478774; b) V. César, S. Bellemin-Laponnaz, L. H. Gade, Chem. Soc. Rev. 2004, 33, 619-636; c) W. A. Herrmann, Angew. Chem. Int. Ed. 2002, 41 1290-1309.

[5] L. Mercs, M. Albrecht, Chem. Soc. Rev. 2010, 39, 1903

[6] For general review on organometallic anticancer drugs, see: a) G. Gasser, I. Ott, N. Metzler-Nolte, J. Med. Chem. 2011, 54, 3-25; b) C. G. Hartinger, N. Metzler-Nolte, P. J. Dyson, Organometallics 2012, 31, 5677-5685.

[7] a) W. Liu, R. Gust, Coord. Chem. Rev. 2016, 329, 191-213; b) M. Mora, M. C. Gimeno, R. Visbal, Chem. Soc. Rev. 2019, 48, 447-462; c) T. Zou C. - N. Lok, P. -K. Wan, Z. -F. Zhang, S. -K. Fung, C. - M Che, Curr Opin. Chem. Biol. 2018, 43, 30-36; d) M. Porchia, M. Pellei, M. Marinelli, F. Tisato, F. Del Bello, C. Santini, Eur. J. Med. Chem. 2018, 146, 709746 ; e) A. Gautier, F. Cisnetti, Metallomics 2012, 4, 23-32; f) S. Y. Hussaini, R. A. Haque, M. R. Razali, J. Organomet. Chem. 2019, 882, 96-111; g) S. Bellemin-Laponnaz, Eur. J. Inorg. Chem. 2020, 10-20.

[8] a) E. Chardon, G. Dahm, G. Guichard, S. Bellemin-Laponnaz, Organometallics 2012, 31, $7618-7621$; b) E. Chardon, G. Dahm, G Guichard, S. Bellemin-Laponnaz, Chem. Asian J. 2013, 8, 1232-1242.

[9] X. Y. Wang, Z. J. Guo, Anti-Cancer Agents Med. Chem. 2007, 7, 19.

\section{Acknowledgements}

This research was funded by La Ligue Contre le Cancer - Grand-Est and by the University of Strasbourg/CNRS - Program IDEX Interdisciplinaire. Dr Lydia Brelot and Corinne Bailly are gratefully acknowledged for X-ray crystallographic analyses.

Keywords: Carbene ligands - Metal complexes - Nitrogen heterocycles $\cdot$ Cytotoxicity $\cdot$ Group 10 metal

[10] M. Sooriyaarachchi, G. N. George, I. J. Pickering, A. Narendran, J. Gailer, Metallomics 2016, 8, 1170

[11] V. Bala, G. Gupta, V. L. Sharam, Mini-Rev. Med. Chem. 2014, 14, 1021.

[12] M. K. Amir, Z. u. Rehman, F. Hayat, S. Z. Khan, G. Hogarth, T. Kondratyuk, J. M. Pezzuto, M. N. Tahir, RSC Advances 2016, 6, 110517.

[13] a) D. Curran, O. Dada, H. Müller-Bunz, M. Rothemund, G. SanchezSanz, R. Schobert, X. Zhu, M. Tacke, Molecules 2018, 23, 2031; b) R. W. -Y. Sun, M. Zhang, D. Li, Z. -F. Zhang, H. Cai, M. Li, Y. -J. Xian, S. W. Ng, A. S. -T. Wong, Chem. Eur. J. 2015, 21, 18534; c) M. Altaf, M. M. u. Mehboob, A. A. A. Seliman, A. A. Isab, V. Dhuna, G. Bhatia, K. Dhuna, J. Organomet. Chem. 2014, 765, 68.

[14] a) M. Skander, P. Retailleau, B. Bourrie, L. Schio, P. Mailliet, A. Marinetti, J. Med. Chem. 2010, 53, 2146-2154; b) M. Chtchigrovsky, L. Eloy, H. Jullien, L. Saker, E. Segal-Bendirdjian, J. Poupon, S. Bombard, T. Cresteil, P. Retail- leau, A. Marinetti, J. Med. Chem. 2013, 56, 20742086.

[15] S. B. Aher, P. N. Muskawar, K. Thenmozhi, P. R. Bhagat, Eur. J. Med. Chem. 2014, 81, 408

[16] N. Chekkat, G. Dahm, E. Chardon, M. Wantz, J. Sitz, M. Decossas, O. Lambert, B. Frisch, R. Rubbiani, G. Gasser, G. Guichard, S. Fournel, S. Bellemin-Laponnaz, Bioconjugate Chem. 2016, 27, 1942.

[17] Y. Ramiro-Cortés, A. Guemez-Gamboa, J. Morán, Int. J. Biochem. Cell. Biol. 2011, 43, 1373.

[18] E. M. Nagy, L. Ronconi, C. Nardon, D. Fregona, Mini-Rev. Med. Chem. 2012, 12, 1216-1229.

[19] A. T. Odularu, P. A. Ajibade, Bioinorg . Chem. Appl. 2019, 8260496. 